\title{
PENERAPAN RELE DIFFERENSIAL DI TRANSFORMATOR 30 MVA
}

\author{
Irine Kartika F \\ Dosen Tetap Yayasan pada program studi teknik elektro \\ Fakultas teknik universitas PGRI Palembang \\ e-mail:irinekartikal@gmail.com
}

\begin{abstract}
ABSTRAK
Alat proteksi pada STL (Sistem Tenaga Listrik) merupakan bagian yang penting di bidang ketenagalistrikan.Gardu Induk merupakan tempat pusat pengatur kebutuhan pembebanan. Di Kota Palembang terdapat banyak tempat yang berkembang pesat namun penyediaan fasilitas energi listriknya tidak seimbang, sehingga fasilitas energi listrik yang ada tidak memadai dari segi kuantitas maupun kualitas. Pada tulisan ini, penulis akan membahas mengenai penerepan rele differensial dimana dalam hal ini akan dibahas mengenai penentuan lokasi, ukuran, dan juga transformator 30 mva. Pembahasan akan mengkaji lebih lanjut mengenai kajian kelayakan operasi dari penggunaan transformator pada daerah yang diteliti. Fungsi proteksi adalah untuk melokalisir gangguan jadi hanya daerah yang terganggu saja yang dibebaskan dari/rangkaian tenaga listrik dan juga harus mempertimbangkan tingkat keamanan terhadap peralatan, stabilitas tenaga listrik dan juga keamanan terhadap manusia Sistem proteksi harus memenuhi persyaratan yaitu Cepat, Aman / Stabil, Peka, Andal dan Selektip sehingga apabila terjadi gangguan maka proteksi akan bekerja sesuai dengan fungsinya sebagai pengaman. ini merupakan perhitungan dan analisis penyetelan koordinasi rele proteksi transformator 30 MVA di gardu induk $70 \mathrm{kV}$, sehingga dari hasil perhitungan dan setting yang benar diharapkan apabila terjadi gangguan rele proteksi akan bekerja dengan baik sesuai dengan fungsi proteksi sebagai pengaman. dilaksanakan.
\end{abstract}

\section{Kata kunci : rele differensial, impedansi, setting rele

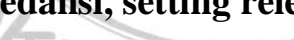

\section{PENDAHULUAN}

Alat proteksi pada STL (Sistem Tenaga Listrik) merupakan bagian yang penting di bidang ketenagalistrikan. Gardu Induk berfungsi sebagai pusat proteksi peralatan-peralatan STL (Sistem Tenaga Listrik) dan sebagai pusat proses penormalan terhadap gangguan-gangguan yang ada. Apabila tidak ada sistem proteksi maka kelangsungan STL tidak selalu tersedia. Sebelum sistem proteksi di implementasikan, diperlukan perhitungan dan analisis agar setting rele dapat diketahui supaya rele dapat bekerja secara baik. Apabila nantinya terjadi gangguan, sebagai contoh overload atau beban lebih, hubung singkat antara fasa dengan fasa, hubung singkat antara fasa dengan tanah maka sistem proteksi akan bekerja sesuai fungsinya sebagai pengaman, sehingga stabilitas tenaga listrik akan berlangsung. Untuk menghindari kejadian gangguan tersebut dan juga untuk mencegah kerusakan transformator $30 \mathrm{MVA}$ maka perlu dilakukan koordinasi proteksi, baik sisi penyulang $20 \mathrm{KV}$ dan sisi 150 KV.Berdasarkan uraian di atas maka bagaimana Transformator 30 MVA yang baru dipasang dan beroperasi sehingga perlu dipasang relay utama dan back up Electric Yaitu Relay differensial.

\section{TINJAUAN PUSTAKA \\ Relay Differensial}

Salah satu komponen yang sangat penting peranannya dalam sistem tenaga listrik adalah transformator tenaga. Transformator tenaga ini berfungsi untuk mengubah besaran teganga, dengan menggunakan transformator tenaga, penyaluran energi dapat luas jangkauannya sehingga Untuk menjaga transformator tenaga dari gangguan diperlukan pengaman. Salah satu pengaman transformator tenaga adalah relay differensial. pada penempatan pembangkitan tidak harus berdekatan dengan beban (Jetri,2007).

Relay differensial digunakan pada peralatan yang secara fisik mempunyai batas daerah proteksi relatif dekat disekitar peralatan tersebut. Jadi relay ini biasanya digunakan pada peralatan seperti : 
transformator, rel dan generator. Biasanya digunakan untuk memproteksi perlatan terhadap gangguan hubung singkat antar fase, maupun fase dengan tanah.

Relay differensial digunakan untuk mengamankan generator dari kerusakan akibat adanya gangguan internal pada kumparan stator. Dua unit transformator arus (CT) masing-masing dipasang pada kedua sisi kumparan generator, Sekunder CT terhubung bintang yang ujung-ujungnya dihubungkan melalui kawat-kawat pilot. Pada kondisi normal dan tidak ada gangguan internal, besarnya arus kedua sisi kumparan sama, sehingga arus yang mengalir pada sisi-sisi sekunder CT juga sama. Hal ini menyebabkan tidak ada arus yang mengalir pada relay. Pada saat terjadi gangguan pada kumparan generator, mungkin fase dengan fase atau fase dengan ground, maka arus yang mengalir pada kedua sisi kumparan akan berbeda, sehingga ada arus yang mengalir pada relay. Relay bekerja menarik kontak sehingga kumparan triping mendapat tenaga dari catudaya searah yang selanjutnya akan menarik kontak pemutus tenaga untuk memutuskan hubungan generator dengan sistem.

Relay differensial merupakan suatu relay yang prinsip kerjanya berdasarkan kesimbangan (balance), yang membandingkan arus-arus sekunder transformator arus (CT) terpasang pada terminalterminal peralatan atau instalasi listrik yang diamankan. Penggunaan relay differensial sebagai relay pengaman, antara lain pada generator, transformator daya, bus bar, dan saluran transmisi.

Relay differensial digunakan sebagai pengaman utama (main protection) pada transformator daya yang berguna untuk mengamankan belitan transformator bila terjadi suatu gangguan. Relay ini sangat selektif dan sistem kerjanya sangat cepat. Prinsip Kerja Dari Relay Differensial Sebagaimana disebutkan diatas, Relay differensial adalah suatu alat proteksi yang sangat cepat bekerjanya dan sangat selektif berdasarkan keseimbangan (balance) yaitu perbandingan arus yang mengalir pada kedua sisi trafo daya melalui suatu perantara yaitu trafo arus (CT).

Dalam kondisi normal, arus mengalir melalui peralatan listrik yang diamankan (generator, transformator dan lain-lainnya). Arus-arus sekunder transformator arus, yaitu $\mathrm{I}_{1}$ dan $\mathrm{I}_{2}$ bersikulasi melalui jalur IA. Jika relay pengaman dipasang antara terminal 1 dan 2 , maka dalam kondisi normal tidak akan ada arus yang mengalir melaluinya.

\section{Rele differensial dalam keadan arus normal}

Gambar 1_menunjukkan rele differensial dalam keadaan arus normal, dimana Ip dan Is sama besar dan berlawanan arah

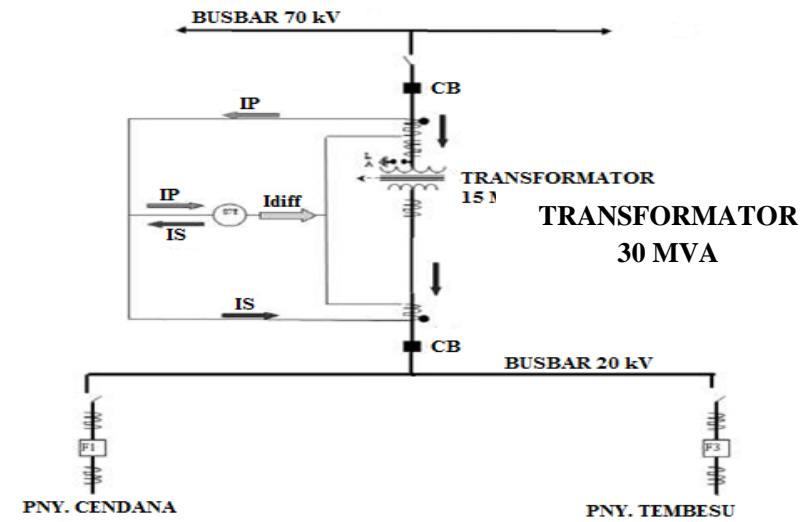

Gambar 1 Rele Differensial Saat Arus Normal

$I \mathrm{~d}=I \mathrm{p}+I \mathrm{~s}=0$ Ampere

Idif $=I \mathrm{P}+I \mathrm{~S}=0$ Ampere

Maka tidak ada tegangan yang melintasi coil rele dan tidak ada arus yang mengalir pada rele tersebut, sehingga rele differensial tidak bekerja

\section{Gangguan Diluar Daerah yang Dilindungi}

Pada gangguan diluar (eksternal) daerah proteksi rele differensial (diluar kedua transformator arus), rele differensial tidak akan bekerja, karena Ip dan Is sama besar dan berlawanan arah 


$$
\begin{aligned}
& (I d=I p+I s=0 \text { Ampere, Idif }=I \mathrm{P}+I \mathrm{~S}=0 \text { Ampere }), \\
& I d=I p+I s>0 \text { Ampere } \\
& I d i f=I \mathrm{P}+I \mathrm{~S}>0 \text { Ampere }
\end{aligned}
$$

Seperti yang ditunjukkan oleh Gambar 2.

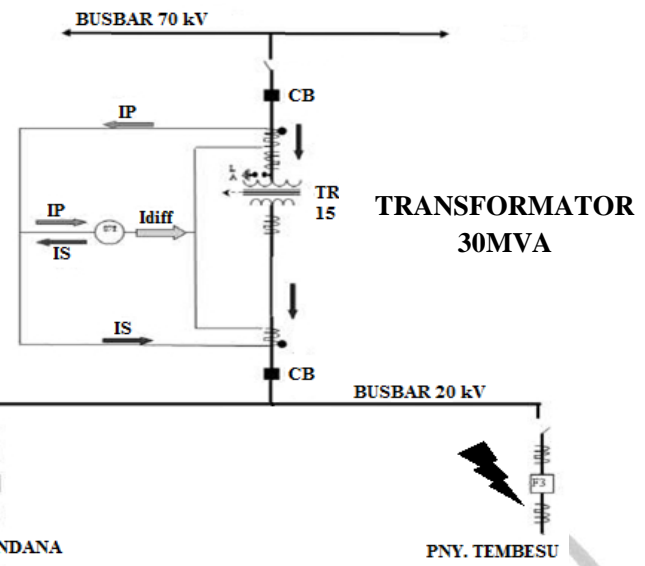

Gambar 2. Rele Differensial Saat Gangguan Eksternal

\section{Gangguan Didalam Daerah yang Dilindungi}

Untuk gangguan didalam (internal) daerah proteksi rele differensial (diantara kedua transformator arus), Ip dan Is searah

a. Gangguan internal

1. Terjadi busur api (arc)

2. Gangguan pada system pendingin

3. Arus sirkulasi pada transformator

\section{b. Gangguan External}

1.External short circuit

2.Overload

Karena arus akan menuju titik gangguan, sehingga rele differensial akan bekerja, seperti yang ditunjukkan pada Gambar 3 .

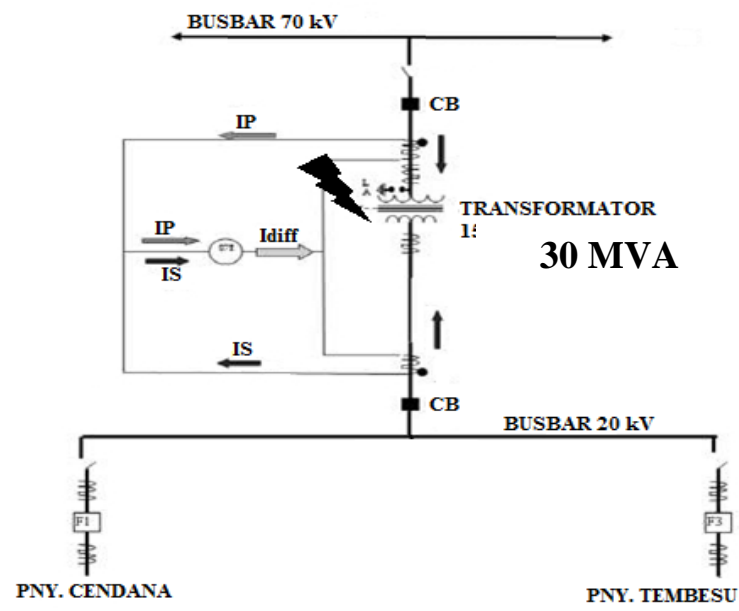

Gambar 3. Rele Differensial Saat Gangguan Internal 
Pada saat ada arus yang mengalir lewat rele, maka rele akan mengirim sinyal pada lock out rele. Sinyal ini akan diteruskan ke C/S dan memerintahkannya untuk lock out sehingga aliran energi listrik terputus, maka transformator tenaga yang diamankan bebas dari pengaruh gangguan yang ada.

\section{Prinsip Kerja Relay Differensial}

Sebagaimana disebutkan diatas, Relay differensial adalah suatu alat proteksi yang sangat cepat bekerjanya dan sangat selektif berdasarkan keseimbangan (balance) yaitu perbandingan arus yang mengalir pada kedua sisi trafo daya.Dalam kondisi normal, arus mengalir melalui peralatan listrik yang diamankan (generator, transformator dan lain-lainnya). Arus-arus sekunder transformator arus, yaitu I1 dan I2 bersikulasi melalui jalur IA. Jika relay pengaman dipasang antara terminal 1 dan 2 , maka dalam kondisi normal tidak akan ada arus yang mengalir melaluinya. Dapat dilihat pada gambar dibawah ini :

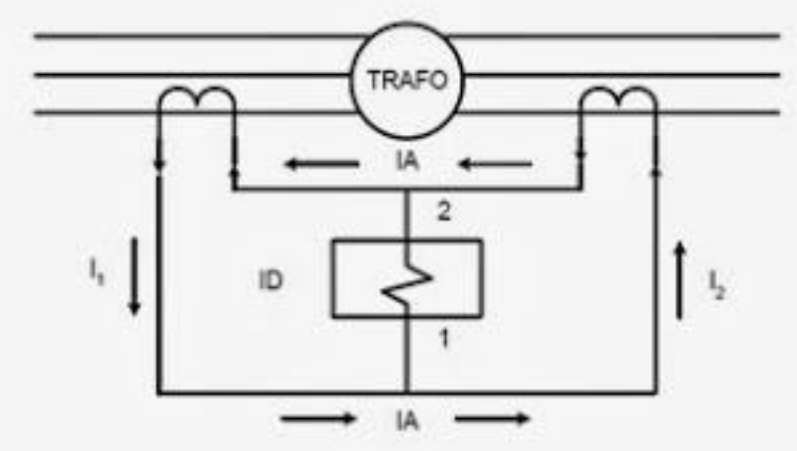

Gambar 4 Pengawatan Dasar Relay Differensial

Jika terjadi gangguan diluar peralatan listrik peralatan listrik yang diamankan (external fault), maka arus yang mengalir akan bertambah besar, akan tetapi sirkulasinya akan tetap sama dengan pada kondisi normal, sehingga relay pengaman tidak akan bekerja untuk gangguan luar tersebut. Jika gangguan terjadi didalam (internal fault), maka arah sirkulasi arus disalah satu sisi akan terbalik, menyebabkan keseimbangan pada kondisi normal terganggu, akibatnya arus ID akan mengalir melalui relay pengaman dari terminal 1 menuju ke terminal 2. Selama arus-arus sekunder transformator arus sama besar, maka tidak akan ada arus yang mengalir melalui kumparan kerja (operating coil) relay pengaman, tetapi setiap gangguan (antar fasa atau ke tanah) yang mengakibatkan sistem keseimbangan terganggu, akan menyebabkan arus mengalir melalui Operating Coil relay pengaman, maka relai pengaman akan bekerja dan memberikan perintah putus (tripping) kepada circuit breaker (CB) sehingga peralatan atau instalasi listrik yang terganggu dapat diisolir dari sistem tenaga listrik. Seperti gambar dibawah ini :

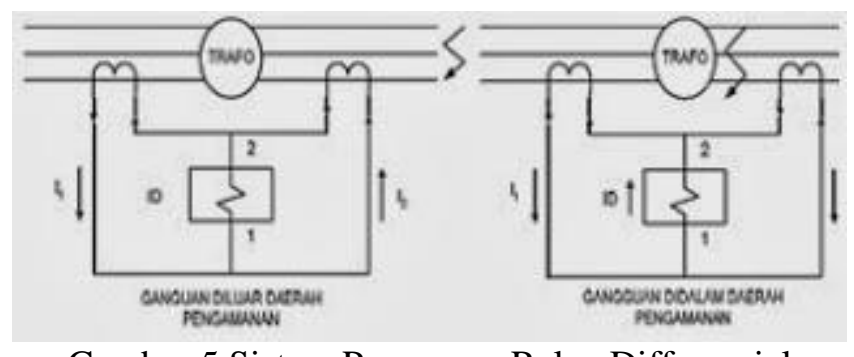

Gambar 5 Sistem Pengaman Relay Differensial

\section{METODE PENELITIAN}

Survei literatur dilakukan untuk meninjau kembali sistem proteksi pada transformator tenaga 30 MVA. Sistem proteksi ini merupakan bagian yang sangat penting dalam suatu instalasi tenaga listrik, selain untuk melindungi peralatan utama bila terjadi gangguan hubung singkat. Sistem proteksi juga 
harus dapat meminimalisir daerah yang terganggu dan memisahkan daerah yang tidak tergangggu, sehingga gangguan tidak meluas dan terhindar dari kerugian yang ditimbulkan.

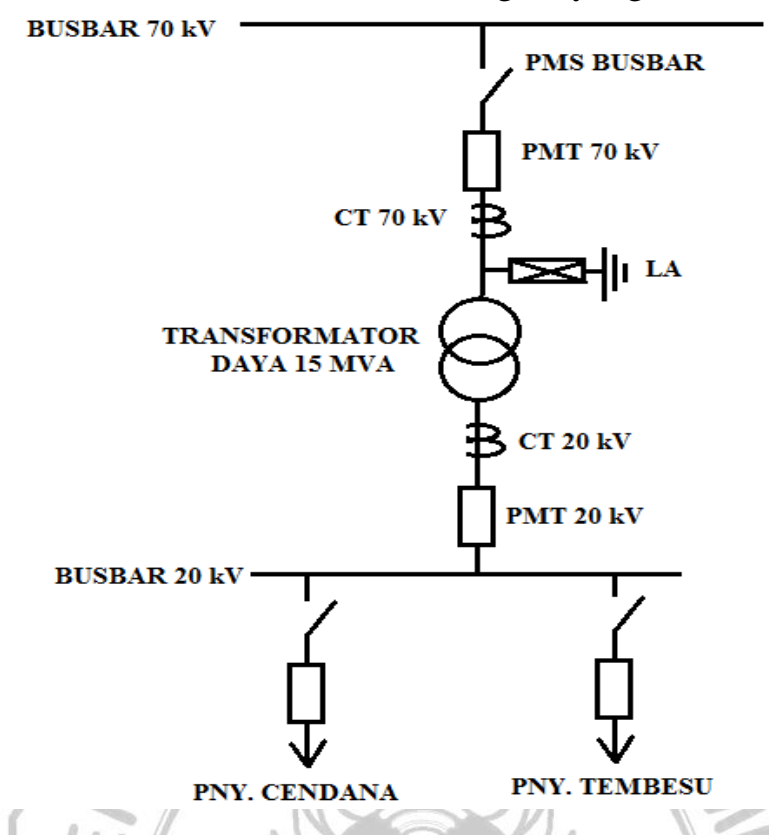

Gambar 6 Single line transformator15 MVA

\section{Gangguan Hubung singkat satu fase ketanah}

Gangguan hubung singkat satu fasa ketanah merupakan gangguan yang sering terjadi.

$$
\mathrm{I}_{r}=\frac{v f}{z_{1}+z_{2}+z_{0}}
$$

Dimana :

$\mathrm{Vf}=$ tegangan

$Z_{1}=$ impedansi urutan positif

$Z_{2}=$ impedansi urutan negatif

$Z_{0}=$ impedansi urutan nol

Untuk menentukan tegangan dalam satuan per unit sebagai berikut :

$$
V_{p u}=v f=\frac{k v^{2} \text { nyata }}{k v^{2} \text { nyata }}
$$

Untuk menentukan $I_{\text {base }}$ sebagai berikut :

$$
I_{\text {base }}=\frac{M V A_{\text {base }}}{\sqrt{3} x v_{\text {base }}} \text {..... }
$$

Dimana :

$$
\begin{aligned}
& M V A_{\text {base }}=\text { daya dasar } \\
& K V_{\text {base }}^{=} \text {tegangan dasar }
\end{aligned}
$$

\section{Impedansi transformator}

Impedansi transformator dapat dihitung dengan menggunakan persamaan sebagai berikut :

$$
\begin{aligned}
& Z_{\text {dasar }}=\frac{K V^{\mathrm{z}}}{M V A} \text {. } \\
& Z_{1}=Z_{2}=\frac{z_{\text {trafo }} x Z_{\text {dasar }}}{30} \\
& Z_{1} \text { (p.u) } \quad=\frac{z_{1}}{z_{\text {dasar }}} . . \\
& Z_{0}=3 \times Z_{1}
\end{aligned}
$$


Dimana :

$$
\begin{aligned}
& Z=\text { impedansi transformator } \% \\
& Z_{1}=\text { impedansi urutan positif }(\mathrm{ohm}) \\
& Z_{2}=\text { impedansi urutan negative }(\mathrm{ohm}) \\
& \mathrm{KV}=\text { tegangan dasar }(\mathrm{KV}) \\
& Z_{\text {d }}=\text { impedansi dasar }(\mathrm{OHM})
\end{aligned}
$$

\section{Relay Differensial}

Relay differensial adalah salah satu rele pengaman utama sistem tenaga listrik yang bekerja seketika tanpa koordinasi rele disekitarnya sehingga waktu kerja dapat dibuat secepat mungkin.

Daerah pengamanannya dibatasi oleh pasangan transformator arus dimana rele differensial dipasang sehingga rele differensial tidak dapat dijadikan sebagai pengaman cadangan untuk daerah berikutnya. Proteksi rele differensial bekerja dengan prinsip keseimbangan arus (current balance).

Prinsip ini berdasarkan hukum kirchhoff yaitu membandingkan jumlah arus masuk ke primer (Ip) cama dancan iumlah arue vana kaluar dari cokunder (IS).

$$
I_{\text {diferensial }}=I_{d}=\left|\overrightarrow{I_{P}}\right|+\left|\overrightarrow{I_{S}}\right|
$$

Dimana:

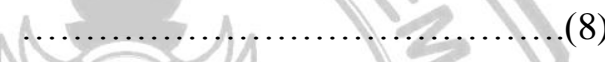

\section{Setting Rele Differensial}

$$
\begin{aligned}
& \mathrm{Id}=\operatorname{Arus} \text { Differensial (A) } \\
& \mathrm{Ip}=\operatorname{Arus} \text { Sisi Masuk (A) } \\
& \mathrm{Is}=\operatorname{Arus} \text { Sisi Keluar (A) }
\end{aligned}
$$

Untuk menghitung arus setting rele differensial dapat menggunakan persamaan :

$$
I_{\text {set }}=\text { slope } \% \times I_{r}
$$

Dimana :

$$
\begin{aligned}
& I_{\text {gat }}=\text { arus setting } \\
& I_{\text {get }}=\text { arus restain }
\end{aligned}
$$

Slope didapat dengan membagi antara komponen arus diferensial dengan arus penahan restain. Slope 1 untuk arus gangguan internal gangguan internal $25 \%$ dan slope 2 untuk arus gangguan eksternal $100 \%$

\section{Arus penahan (restrain)}

Arus penahan (restrain) didapat dari arus maksimal komponen arus sekunder perfasa dibelitan $1(\mid \overrightarrow{I 1}])$ dan belitan $2(\mid \overrightarrow{I 2}])$

$$
\begin{aligned}
& I_{\text {restrain }}=I_{r} \\
& \quad=\max (\lfloor\overrightarrow{I 1}\rfloor),(\lfloor\overrightarrow{I 2}\rfloor)
\end{aligned}
$$

Untuk menghitung arus penahan (restrain) ketika terjadi gangguan sebagai berikut :

$$
I_{\text {restrain }}=\frac{I P+I S}{2}
$$

Dimana :

$$
I_{r}=\operatorname{arus} \text { penahan }(\mathrm{A})
$$




$$
\begin{aligned}
& I_{p}=\operatorname{Arus} \text { primer }(\mathrm{A}) \\
& I_{s}=\operatorname{arus~sekunder}(\mathrm{A})
\end{aligned}
$$

Untuk menghitung arus differensial (operasi) dapat menggunakan persamaan sebagai berikut :

$$
I_{d}=I_{1}+I_{2}
$$

Dimana :

$$
\begin{aligned}
& I_{r}=\operatorname{arus} \operatorname{differensial}(\mathrm{A}) \\
& I_{r}=\operatorname{arus} \operatorname{primer}(\mathrm{A}) \\
& I_{r}=\operatorname{arus} \operatorname{sekunder}(\mathrm{A})
\end{aligned}
$$

HASIL DAN PEMBAHASAN

Data relay differensial

Tabel 1. Data relay differensial dan relay OCR

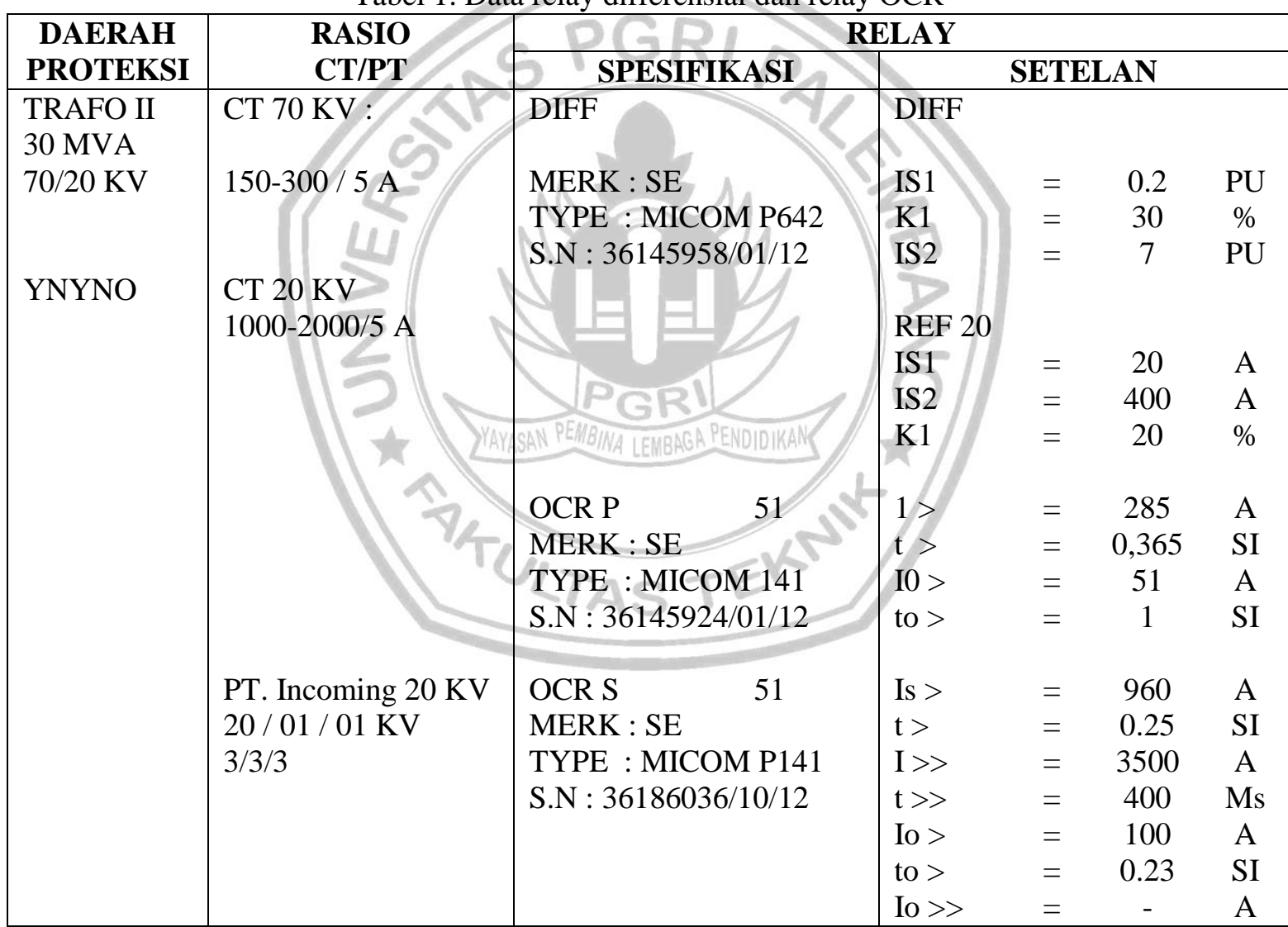

Tabel 2. Data Transformator

\begin{tabular}{|l|l|}
\hline \multicolumn{2}{|c|}{ Tegangan 70 KV } \\
\hline Sisi Primer & $400 \mathrm{~A}$ \\
\hline Sisi Sekunder & $5 \mathrm{~A}$ \\
\hline Perhitungan & $400: 5$ \\
\hline
\end{tabular}

Tabel 3. Data Proteksi

\begin{tabular}{|c|c|}
\hline \multicolumn{2}{|c|}{ Rele Differensial } \\
\hline Type & Schenider \\
\hline Merk & MiCOM \\
\hline ACT & Ttad \\
\hline
\end{tabular}


Perhitungan Impedansi Transformator

$$
\begin{aligned}
Z_{\text {dasar }} & =\frac{K V^{2}}{M V A} \\
& =\frac{70^{2} \mathrm{kv}}{30 \mathrm{MVA}} \\
& =163 \mathrm{ohm} \\
Z_{1} & =Z_{2}=\frac{z_{\text {trafo }} x Z_{\text {dasar }}}{30} \\
& =\frac{12,45 \times 163}{30} \\
& =67,7 \mathrm{ohm} \\
Z_{1}(p u) & =\frac{Z_{1}}{z_{\text {dasar }}} \\
& =\frac{67,7}{163} \\
& =0,415 \mathrm{pu} \\
Z_{0} & =3 \times Z_{1} \\
& =3 \times 0,415 \\
& =1,245 \mathrm{pu}
\end{aligned}
$$

Perhitungan Arus gangguan hubung singkat 1 fasa ke tanah

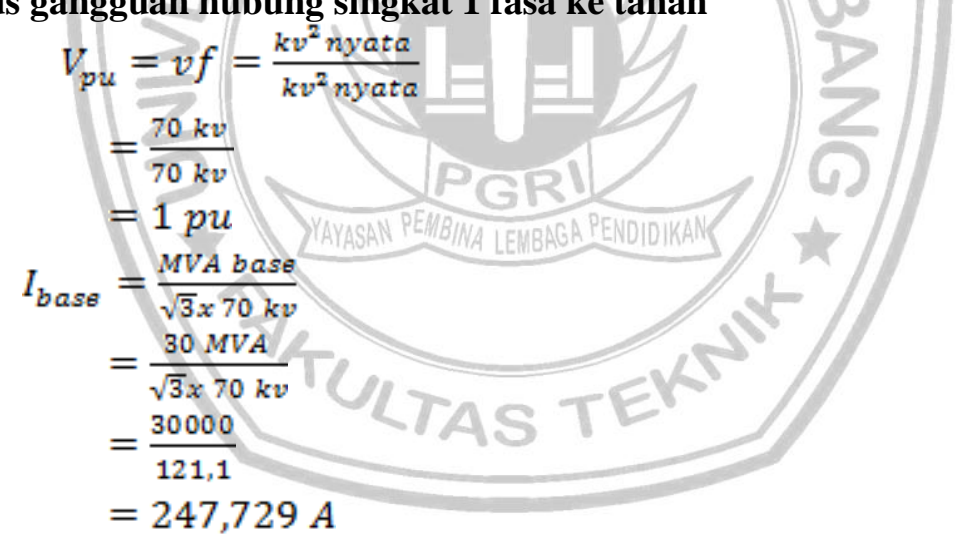

Untuk menghitung besarannya arus gangguan satu fasa ketanah sebagai berikut:

$$
\begin{aligned}
\mathrm{I}_{r} & =\frac{v f}{z_{1}+z_{2}+z_{0}} \\
& =\frac{1}{0,415+0,415+1,245} \\
& =2,075 \mathrm{pu}
\end{aligned}
$$

Jadi besarnya arus gangguan satu fasa ke tanah $\left(I_{r}\right)$

$$
\begin{aligned}
I_{r} & =I_{\text {fasa ketanah }} X I_{\text {base }} \\
& =2,075 \times 247,729 \\
& =514,037 \mathrm{~A}
\end{aligned}
$$

\section{Perhitungan Arus Primer Dan Arus Sekunder}

Dimana:

$$
\text { Id }=\text { Ip + Is }
$$

$$
\begin{aligned}
& \text { Id }=\text { Arus Differensial (A) } \\
& \text { Ip }=\operatorname{Arus~Sisi~Masuk~(A)~} \\
& \text { Is }=\operatorname{Arus~Sisi~Keluar~(A)~}
\end{aligned}
$$


a. Menentukan Ip menggunakan persamaan 3.1 yaitu.

$$
\begin{gathered}
I p=\frac{M V A}{K V \sqrt{3}} \\
I p=\frac{30000 \mathrm{KA}}{70 \mathrm{KV} \sqrt{3}} \\
=\frac{30000}{121,243} \\
=247,435 \mathrm{~A} \\
\text { Maka, Ip } p_{c t}=\frac{247_{0}, 435}{150} \times 5 \\
=8,25 \mathrm{Ip}
\end{gathered}
$$

b. Menentukan Is menggunakan persamaan 3.1 yaitu.

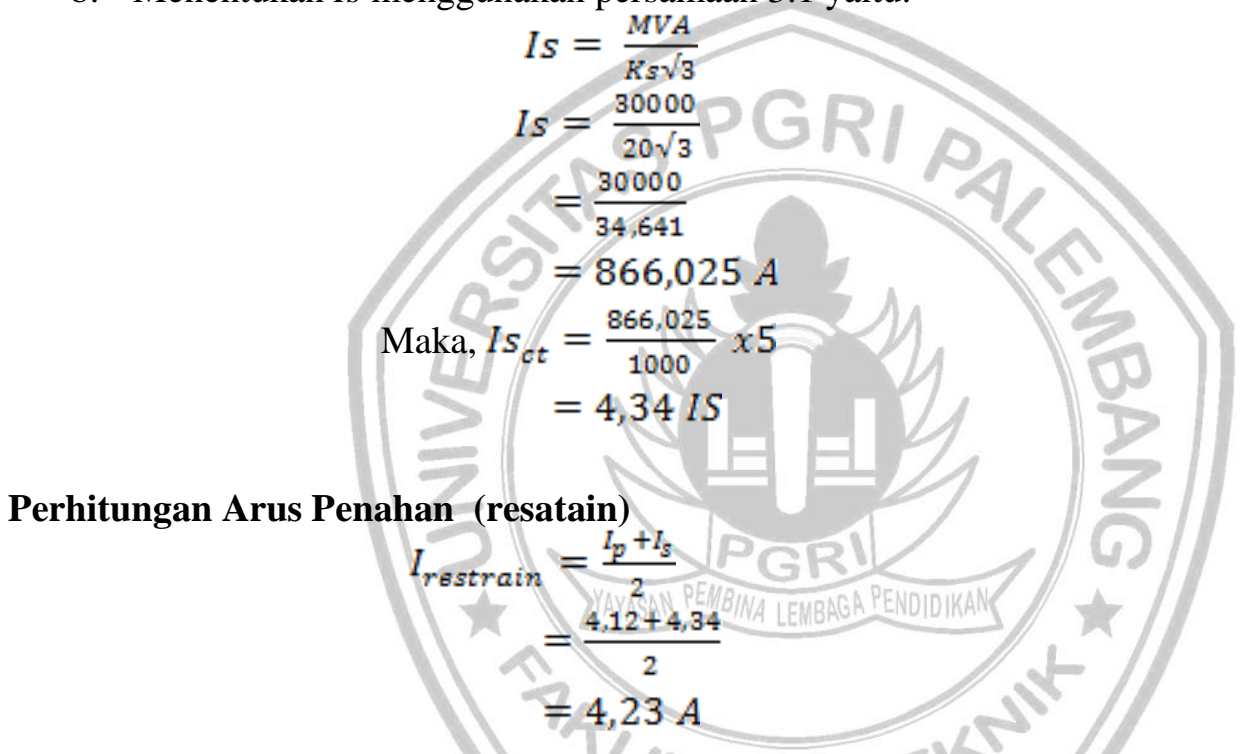

Perhitungan Setting Rele Differensial pada Transformator 3.2 Yaitu

$$
\begin{aligned}
& \frac{I d}{I r} \times 100 \% \\
& =\frac{0,31}{5} \times 100 \% \\
& =5,2 \%
\end{aligned}
$$

Jadi, Tetapan PLN tambahkan 20 untuk Slope dari 5,2\% menjadi 25\%

$$
\begin{aligned}
\text { Iset } & =\text { slopex Ir } \\
& =25 \% \times 5,0 \\
& =1,30 \mathrm{~A}
\end{aligned}
$$

Jadi setting differensial sebesar 1,30 Ampere

Untuk menghitung arus differensial dapat menggunakan persamaan sebagai berikut : Jadi, Id yang diketahui

$$
\begin{aligned}
I d & =I p+I s \\
& =4,12+(-4,43) \\
& =0,31
\end{aligned}
$$

Jadi, Id adalah $0,31 \mathrm{~A}$ 
Untuk gangguan internal pada transformator yaitu membandingkan antara arus setting rele differensial

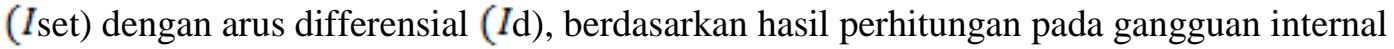
transformator adalah Iset $<\mathrm{Id}$, maka rele differensial trip.

$\begin{array}{ll}\text { Id } & =1,786 \mathrm{~A} \\ \text { Iset } & =0,223 \mathrm{~A}\end{array}$

Berdasarkan hasil perhitungan di atas ,maka didapat setting relay differensial sebesar 1,30 A dengan setelan arus yang digunakan 0,45 sampai 0,9 A. dan besarnya kapasitas transformator arus yang akan dipasang pada sisi primer dan sisi sekunder dari transformator daya. Untuk sisi tegangan primer arus nominal (In) dalam perhitungan adalah sebesar 247,435 $\mathrm{A}$ dan berdasarkan setandar yang telah ditentukan besarnya kapasitas transformator arus yang mendekati $247,435 \mathrm{~A}$ adalah $250 \mathrm{~A}$, jadi nilai Arus sisi masuk (Ip) 8,25. untuk sisi tegangan sekunder arus nominal (In) dalam perhitungan adalah sebesar $866,025 \mathrm{~A}$ dan berdasarkan standar yang telah ditentukan besarnya kapasitas transformator arus yang mendekati 866,025 A adalah $900 \mathrm{~A}$, jadi nilai Arus Sisi keluar (Is) sebesar 4,34 sedangkan nilai arus differensial (Id) yang di dapat adalah 0,31 A dan nilai slope sebesar menjadi $26 \%$.

\section{KESIMPULAN}

Setelah di ambil perhitungan dan hasil pembahasan,maka dapat di simpulkan bahwa :

1. Reaktansi transformator daya sebesar 0,119 p.u, impendansi urutan positif dan negative sebesar 0,0186 p.u, impedansi urutan nol sebesar 1,488 p.u, arus nominal primer 4,99,03 A, arus nominal sekunder sebesar 307,92 A arus gangguan satu fasa ketanah sisi primer dan sisi sekunder sebesar 17,32 A dan 34,98 A

2. hasil perhitungan setting relay differensial, di dapat perbandingan antara perhitungan dengan standar setelan arus dari hasil perhitungan setting relay differensial sebesar 1,30 A, hasil perhitungan proteksi arus dan waktu gangguan pada Transformator 30 MVA menunjukan bahwa terdapat perbedaan arus dan waktu antara gangguan yang diasumsikan pada keadaan $110 \% 125 \%$ dan $150 \%$ pada keadaan $110 \%$ arusnya ialah 3049,42 ampere.

\section{DAFTAR PUSTAKA}

1. Jetri, Studi Penyetelan Rele Differensial Pada Transformator PT.Petron Pacific Indonesia, downlood.portalgaruda.org/article.php?....STUDI\%PENYETELA...,diakses November 2016

2. Pandjaitan Bonar, Praktik - praktik Proteksi Sistem Tenaga Listrik, Yogyakarta. Penerbit Andi, 2012

3. Sarimun N. Wahyudi, Proteksi Sistem Distribusi Tenaga Listrik, Depok, Garamond, edisi pertama, April 2006

4. Stevenson,jr William D, Analisis Sistem Tenaga Listrik, Jakarta, Erlangga, 1983. 